\title{
Mama supernumeraria vs. liposarcoma Presentación de un caso $* * * *$
}

\author{
Aristides Di Zeo Galiano*; Alberto Saumeth**; Guillermo Acosta Osio***
}

El día 14-VI-91 consulta al Departamento de Ginecología y Obstetricia del Hospital Universitario Metropolitano, paciente femenina de 23 años de edad, natural, residente y procedente de Soledad (Atlántico), casada, ama de casa, quien refiere tener el seno izquierdo inflamado.

Manifiesta la paciente que en la cara interna de su brazo izquierdo aproximadamente en marzo de 1990 empezó a crecer tumoración semejante a un seno, con presencia de una formación que parecía corresponder al pezón. A partir de su último parto el 21 de marzo de 1991, presentó aumento de tamaño además de salida de secreción serosanguinolenta por el pezón y acompañada de dolor tipo pulsátil.

Entre los antecedentes personales y familiares no hubo ningún dato positivo ni importante.

FGO: Menarquía: 12 años. Ciclo: 30 x 8 días.

En su puerpuerio tardío pos-parto eutócico.

$\mathrm{G}_{3} \mathrm{P}_{4}$ Ao El tercer parto gemelar.

No refiere antecedentes ni complicaciones obstétricas.

Figura 1

VISION GLOBAL DE LA PACIENTE EL PRIMER DIA DE CONSULTA. ASPECTO A LA INSPECCION DE LA PACIENTE EL DIA DEL INGRESO

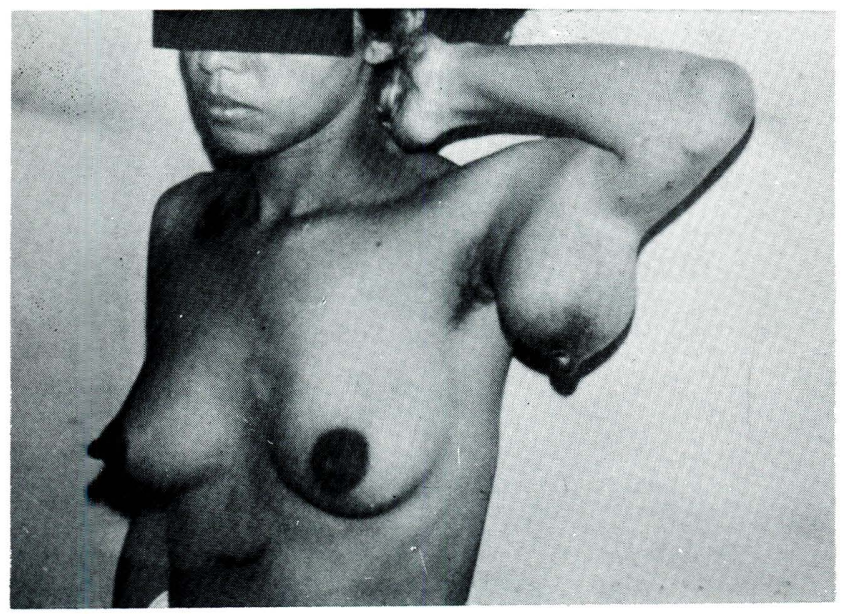

* Residente I Año Ginecología y Obstetricia. Hospital Universitario Metropolitano.

** Profesor Departamento de Cirugía. Hospital Universitario Metropolitano.

*** Director Departamento de Ginecología y Obstetricia. Hospital Universitario Metropolitano.

**** Mención honorífica: Primer puesto al mejor trabajo presentado en modalidad de Posters en el XVIII Congreso Colombiano de Obstetricia y Ginecología, Barranquilla diciembre 4 al 7 de 1991.

\section{Examen físico:}

Datos positivos: mamas turgentes, secretantes y simétricas; en la cara interna del brazo izquierdo presenta masa de 11 x $13 \mathrm{~cm}$. Con pezón y secreción serosanguinolenta; a la palpación se encuentra tejido renitente, con escaso dolor a la movilización, y no fija a planos profundos.

Se realizan los siguientes diagnósticos:

1) Puerpuerio tardío por parto eutócico.

2) Mama supernumeraria con mastitis.

PLAN: Antibioticoterapia

Analgésicos

Y biopsia excisional.

Figura 2

PLACA DE RAYOS X, DONDE SE OBSERVA (MASA SIN

CALCIFICACIONES TOTALMENTE LIBRE). LESION

LIMITADA A LOS TEJIDOS BLANDOS, SIN CALCIFICACIONES. ESTRUCTURAS OSEAS SIN ALTERACIONES

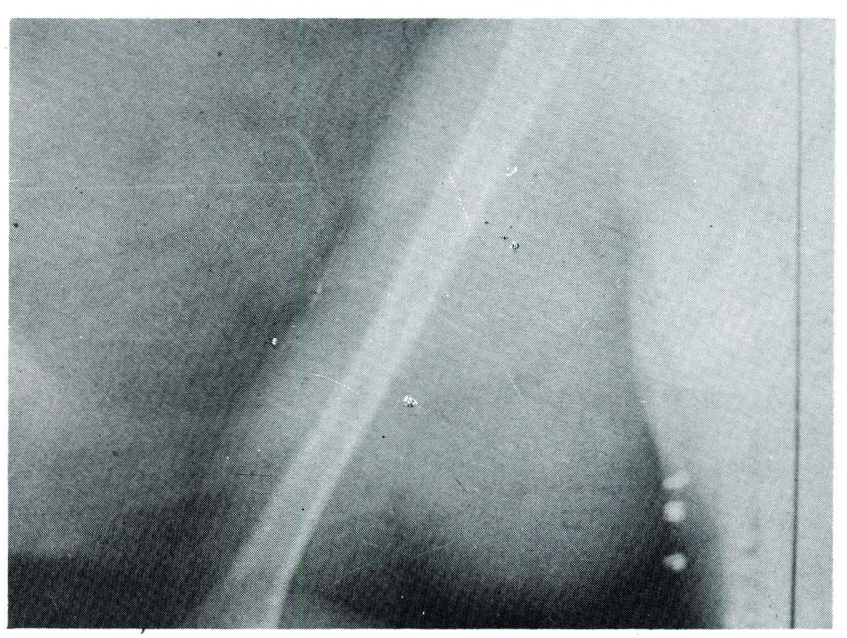

El 15-VI-91 se realizó la biopsia y el reporte de patología informa: Liposarcoma bien diferenciado con áreas mixoides focales.

Regresa el 17-VII-91 con masa que se ha reproducido en el área de la biopsia de aproximadamente de $6 \times 4 \mathrm{~cm}$., por lo cual el 19-VIII-91 se reinterviene y se reseca piel, tejido celular subcutáneo y pequeña porción de biceps, dejando bordes libres, lo cual se confirma microscópicamente por patología.

Se complementa el tratamiento con radioterapia por cuatro semanas y hasta el momento no ha vuelto a crecer ni presentar molestias. 
Figura 3

VISUALIZACION DE LA FUTURA INCISION QUIRURGICA A REALIZARSE. LIMITE DE LA INCISION QUIRURGICA

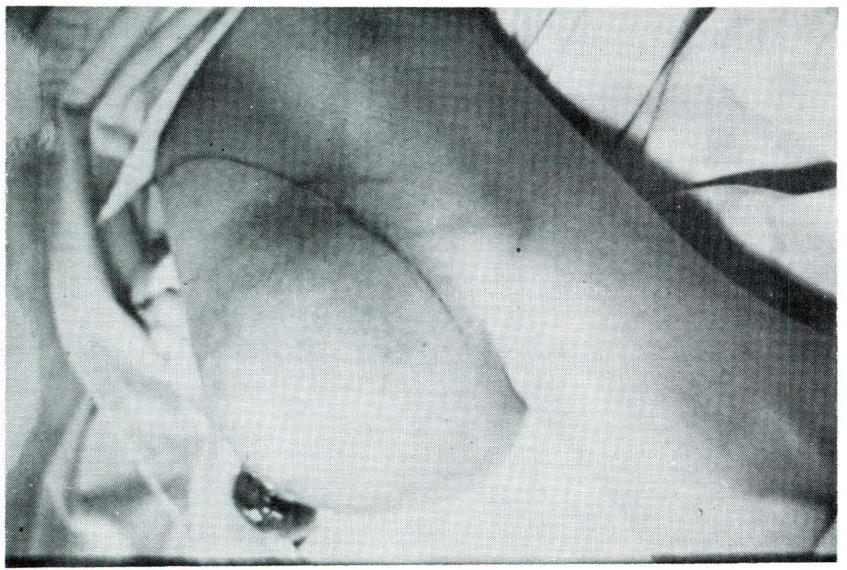

\section{Comentarios}

El liposarcoma es un tumor mesenquimatoso poco frecuente, que se origina en tejidos profundos, con una incidencia hasta del 20\%; rara vez de metastasis, y en caso tal su supervivencia a cinco años es menor del $20 \%$. No tiene predilección por sexo alguno.

Se presenta con mayor frecuencia entre los 20 y los 30 años de edad. Su localización más frecuente es en muslos, glúteos, región poplítea y región inguinal. La localización del tumor en éstas pacientes es muy rara y más aún en período
Figura 4

EXPOSICION QUIRURGICA (DE LA MASA A EXTRAERSE) $Y$ ASPECTO DE LA LESION TUMORAL IN SITU

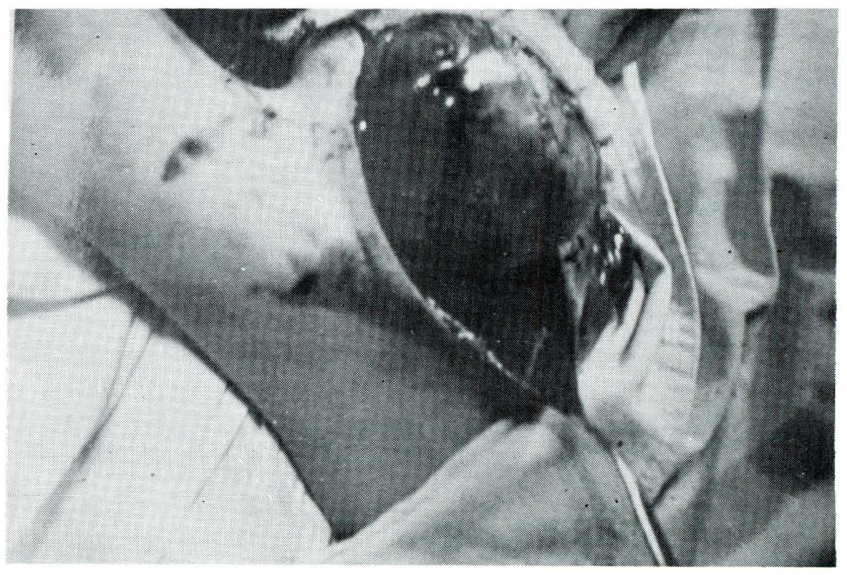

pre y post parto, lo cual dificultó un tanto el diagnóstico, que se realizó con la biopsia.

El tratamiento curativo es la excisión quirúrgica. Es radiosensible en forma variable y su pronóstico es bueno si no ha dado metastasis.

\section{BIBLIOGRAFIA}

Stanly. Patología Humana. Editorial Mac-Graw-Hill, 4a. edición. México, $1990 ; 232$.

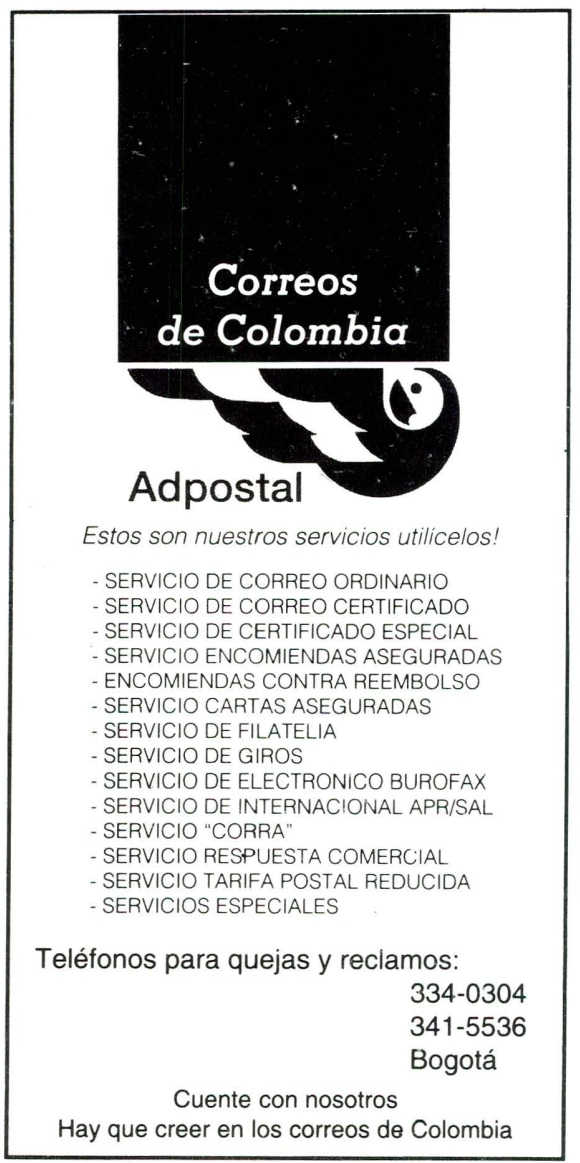

